\title{
EFFECTS OF CHINESE HERBS ON THE HEMAGGLUTINATION AND ADHESION OF ESCHERICHIA COLI STRAIN IN VITRO
}

\author{
YanQing Tong* ${ }^{*}$, Qiucheng $\mathrm{Wu}^{1}$ ， DongKai Zhao ${ }^{1}$, Yanru Liu ${ }^{1}$ ， Mingming Cao ${ }^{1}$, Liping \\ Zhang $^{2}$, Shiming Zeng ${ }^{2}$
}

${ }^{1}$ Department of Nephrology, The First Affilliated Hospital to Changchun University of Chinese Medicine, Changchun city, Jilin province, China. ${ }^{2}$ Department of Microbiology, The Northeast Normal University, Changchun city, Jilin province, China.

Email: tyq1229@yahoo.com.cn

\begin{abstract}
The aim of this study is to evaluate Chinese herbs' efficacy on adhesive properties of Escherichia coli (E. coli). The effects of Chinese herbal solution on the hemagglutination and adhesion by E. coli strain were studied. E. coli C16 was isolated from a patient with urinary tract infection. The MIC value of herbal solution for the E. coli C16 was $0.1 \mathrm{~g} / \mathrm{ml}$. The MBC value was $0.2 \mathrm{~g} / \mathrm{ml}$. The effects of herbal solution on the hemagglutination abilities of $E$. coli $\mathrm{C} 16$ were dependent on the herbal solution used. The strain C16 lost half of its hemagglutination abilities when the herbal solution concentration was at MIC $(0.05 \mathrm{~g} / \mathrm{ml})$. Herbal solution decreased the adherence of strain C16 in a dose-dependent way. The numbers of adherent bacteria were reduced to $45 \%$ of the control values after growth with herbal solution at MIC. The results show that anti-adhesion is one mode of action for Chinese herbs used against pathogens.
\end{abstract}

Key words: Chinese herbs; Escherichia coli; Adhesion; Hemagglutination.

\section{Introduction}

The adhesion of bacteria to uroepithelial cells and urinary catheters is the first step in the development of a urinary tract infection (UTI) (Beachey, 1981). Anti-adhesion is a highly promising approach to fight against pathogens in the era of increasing antibiotic resistance. Escherichia coli (E. coli) is the most common cause of UTI (Kahlmeter, 2003). About 90\% of acute pyelonephritis cases are caused by E. coli expressing type P-fimbriae (Kärkkäinen, et al., 1998). E. coli strains isolated from patients with upper UTI have been shown to adhere more frequently to human uroepithelial cells than those isolated from patients with asymptomatic lower-tract infections or from normal faeces (Edén et al., 1976).

Although UTI is usually treated with common antimicrobial agents, concerns about antibiotic resistance, side effects, and prevention of recurrent UTIs in susceptible populations have led to increased interest in using other remedies to prevent bacterial infections. UTI prevention through the use of the Chinese herbs is being investigated.

Traditional Chinese medicine (TCM) is a system of healing that originated thousands of years ago. It has evolved into a well-developed, coherent system of medicine that uses several modalities to treat and prevent illness. The most commonly employed therapeutic methods in TCM include Chinese herbal medicine, acupuncture/moxibustion, diet therapy, mind/body exercises (Qigong and Tai Chi), and Tui Na (Chinese massage) (Lao, 1999). Herbal medicine has been an integral part of TCM for more than 2000 years. Many herbal formulations have been developed and are used in the treatment of UTI. In our preliminary study, favorable results were obtained in UTI patients administered some Chinese herbs. But very little is known about its mode of action. In an attempt to learn these Chinese herbs' efficacy on adhesive properties of pathogens, we have studied its action on E. coli. 


\section{Materials and Methods}

\section{Bacterial strains}

E. coli $\mathrm{C} 16$ isolated from a patient with UTI in the First Affilliated Hospital to Changchun University of Chinese Medicine (Changchun city, Jilin province, China) was used in this investigation because it produced hemolysin freely in culture. The isolation and identification of $E$. coli C16 were according to methods recommended by Olsson et al (1982).

\section{Preparation of Chinese herbs}

The Chinese herbs were prepared by the following ratio: Tong Cao (Stachyurus himalaicus Hook.f.et Thoms) 4 : Hua Shi (Talcum spp.) 20 : Chi Shao (Paeonia lactiflora Pall.) 20 : Hui Xiang (Foeniculum vulgare Mill.) 30 : Guan Gui (Cinnamomum cassia Presl) 30 : Li Zhihe (Litchi chinensis Sonn) 30 : Tian Kuizi (Semiaquilegia adoxoides (DC.) makino) 30 : Zihua Diding (Viola ycdoensis Mak.) 30 : Ju Mai (Dianthus superbus L.] 40 : Ma Chixian (Portulaca oleracea L) 60 : $\mathrm{Pu}$ Gongying (Herba taraxaci) 60. The eleven crude drugs were mixed in $800 \mathrm{ml}$ water $\left(100^{\circ} \mathrm{C}\right.$ for 30 mins twice), leaving $100 \mathrm{ml}$ liquor after decanting the mixture. The liquor was centrifuged, filtered and sterilized with the solution of $0.5 \mathrm{~g} / \mathrm{ml}$ as the drug concentration.

\section{Media and growth conditions}

For growth on solid medium, strains were streaked onto Luria-Bertani (LB) agar plates (per liter, $10 \mathrm{~g}$ tryptone, $5 \mathrm{~g}$ yeast extract, $0.5 \mathrm{~g} \mathrm{NaCl}, 15 \mathrm{~g}$ agar) and incubated at $37^{\circ} \mathrm{C}$ for $18 \mathrm{hr}$. For growth in liquid culture, strains were inoculated into LB broth (per liter, $10 \mathrm{~g}$ tryptone, $5 \mathrm{~g}$ yeast extract, $0.5 \mathrm{~g} \mathrm{NaCl})$ and incubated at $37^{\circ} \mathrm{C}$ for $18 \mathrm{hr}$ with aeration $(200 \mathrm{rpm})$. Liquid cultures were incubated without shaking. All plates were inoculated with $10^{8}$ bacteria.

\section{Determination of minimal inhibitory concentration (MIC) and minimal bactericidal concentration (MBC)}

The MIC of herbal solution for E. coli C16 was determined as follows: Starting with the $0.5 \mathrm{~g} / \mathrm{ml}$ concentration, seven serial dilutions were prepared in LB agar $(0.5 \mathrm{~g} / \mathrm{ml}, 0.2 \mathrm{~g} / \mathrm{ml}, 0.1 \mathrm{~g} / \mathrm{ml}, 0.05 \mathrm{~g} / \mathrm{ml}, 0.025 \mathrm{~g} / \mathrm{ml}, 0.0125 \mathrm{~g} / \mathrm{ml}$ and $0.0 \mathrm{~g} / \mathrm{ml})$. These concentrations were inoculated with representative bacterial strain (E. coli C16) as described above. The MIC was the lowest concentration of herbal solution that prevented obvious turbidity after incubation for $18 \mathrm{hr}$ at $37^{\circ} \mathrm{C}$. The MBC was determined according to the MIC. The lowest concentration without visible growth corresponded to the MBC.

\section{Hemagglutination tests}

Hemagglutination with human P erythrocytes were performed as described earlier (Korhonen, 1979). Human erythrocytes were provided by one of the authors (Yanqing Tong). The erythrocytes were washed with PBS and suspended into a $2 \%$ (vol/vol) suspension (in PBS). Slide hemagglutinations were performed with a cooled erythrocyte suspension over crushed ice. In titrations, the microtiterplates were kept at $4{ }^{\circ} \mathrm{C}$ for $2 \mathrm{hr}$ before the results were recorded. All hemagglutinations were performed in the presence of $\alpha$-methyl-D-mannoside (Sigma-Aldrich, Germany) to prevent the interference by the type 1 fimbriae.

\section{Adherence to human uroepithelial cells}

Human uroepithelial cells were collected from the freshly voided urine of one healthy woman without history of 
UTI. To collect these cells, $30 \mathrm{ml}$ of urine was filtered slowly under low vacuum on a 12-jim Sartorius Membranfilter (Sartorius Membranfilter GmbH., Germany) until a small volume was left. This residue was washed three times with phosphate-buffered saline (PBS, pH 7.0). After the third washing, the residue was filtered down completely, allowing the epithelial cells to settle on the filter at random. The epithelial cells were transferred to a glass cover slip ( 9 by $32 \mathrm{~mm}$ ) by pressing the cover slip on the filter. The cover slip with epithelial cells was placed in a Leighton tube and dried for 15 mins. The adherence assays were performed in these tubes. Bacteria were grown overnight in nutrient broth (Oxoid, London, England) with gentle agitation at $37^{\circ} \mathrm{C}$. Cells were spun down and suspended carefully in PBS to a concentration of $10^{8} / \mathrm{ml}$.

For adherence assays, $5 \mathrm{ml}$ of the bacterial suspension was added to a Leighton tube containing a cover slip with attached epithelial cells, and incubated for $1 \mathrm{hr}$ with gentle shaking at $37^{\circ} \mathrm{C}$. The cover slip was removed from the Leighton tube and washed twice with PBS to remove bacteria that had not adhered. The epithelial cells were fixed for $15 \mathrm{~min}$ in methanol, washed twice again with PBS, and stained for 20 mins with 30\% filtered Giemsa stain (Giemsas-L6sung; Merck, Darmstadt, Germany). After two washings with distilled water, the cover slip was dried in the air and mounted upside down on a glass slide.

To determine the inhibition of adherence by herbal solution, the assay was carried out in the presence of herbal solution (MIC), together with an assay on the same strain without Wenyantonglin to serve as a control. In each assay a control experiment was included without added bacteria, to determine the possible presence of extraneous bacteria on the epithelial cells. Each strain was tested at least twice, on different days. Adherence was examined with a light microscope at $\times 400$ magnification and expressed as the percentage of epithelial cells with more than 25 adherent bacteria out of a total of 50 cells counted. The counted cells were of about equal size and were randomly chosen.

\section{Results and Discussion}

The MIC value of herbal solution was $0.1 \mathrm{~g} / \mathrm{ml}$ for the $E$. coli $\mathrm{C} 16$. The MBC value was $0.2 \mathrm{~g} / \mathrm{ml}$ (Figure 1 ).

Human erythrocytes express glycolipids with the Gala1-4Gal disaccharide on their surface and therefore hemagglutination assay can be utilized in the adhesion inhibition studies of bacteria binding (Kallenius et al., 1980). The effects of herbal solution on the hemagglutination abilities of E. coli $\mathrm{C} 16$ were tested by titrating standardized suspensions of control and herbal-solution-treated bacteria against a $2 \%$ suspension of human erythrocytes. The effects were dependent on the herbal solution used. The herbal solution reduced the titer with strain C16 in a dose-dependent way. The strain C16 lost half of its hemagglutination abilities when the herbal solution concentration was at MIC $(0.05 \mathrm{~g} / \mathrm{ml})$ (Figure 2).

The role of herbal solution on the adhesion to human uroepithelial cells was evaluated. In parallel with its effects on hemagglutination, herbal solution reduced the adhesion of the bacteria to human uroepithelial cells. Herbal solution decreased the adherence of strain C16 in a dose-dependent way. The number of adherent bacteria was reduced to $45 \%$ of the control values after growth with herbal solution at MIC (Figure 3).

Some Chinese herbs in the experiment were shown to have antibacterial activity (Tong et al., 2006). These properties have prompted their compound prescription use in the management of UTI. With that in mind, we analyzed the effects of these Chinese herbs on bacterial adhesion.

By attaching to mucous surfaces, bacteria can resist the cleansing action of fluids such as urine. This is often the first step in infection. E. coli C16 was a Pap-fimbriated clinical isolate from a UTI patient. In this study, growth in the presence of herbal solution decreased the hemagglutination titer (used as a measure of adhesion) of E. coli C16. The effect was in a dose-dependent manner. In parallel with the decrease in hemagglutination, the herbal solution also decreased the adhesion of E. coli strain C16 to human uroepithelial cells. The herbal solution reduced the adhesion in a way similar to that of the reduction of hemagglutination. The effect on hemagglutination was clearer; this is probably because the test for hemagglutination is more sensitive and quantifiable than that for adhesion. The results show that anti-adhesion is one mode 


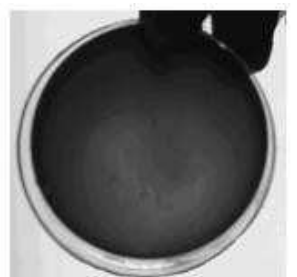

(A)

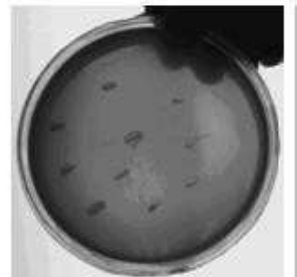

(B)

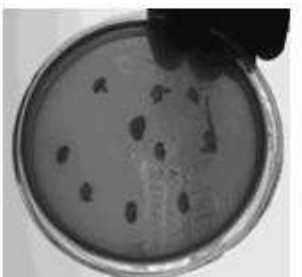

(C)

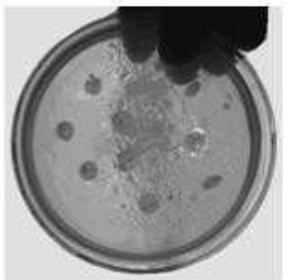

(D)

Figure 1: Determination of MIC and MBC of herbal solution for E. coli C16. (A) $0.2 \mathrm{~g} / \mathrm{ml}$ herbal solution concentration; (B) $0.1 \mathrm{~g} / \mathrm{ml}$ herbal solution concentration; (C) $0.05 \mathrm{~g} / \mathrm{ml}$ herbal solution concentration; (D) $0.0 \mathrm{~g} / \mathrm{ml}$ herbal solution concentration

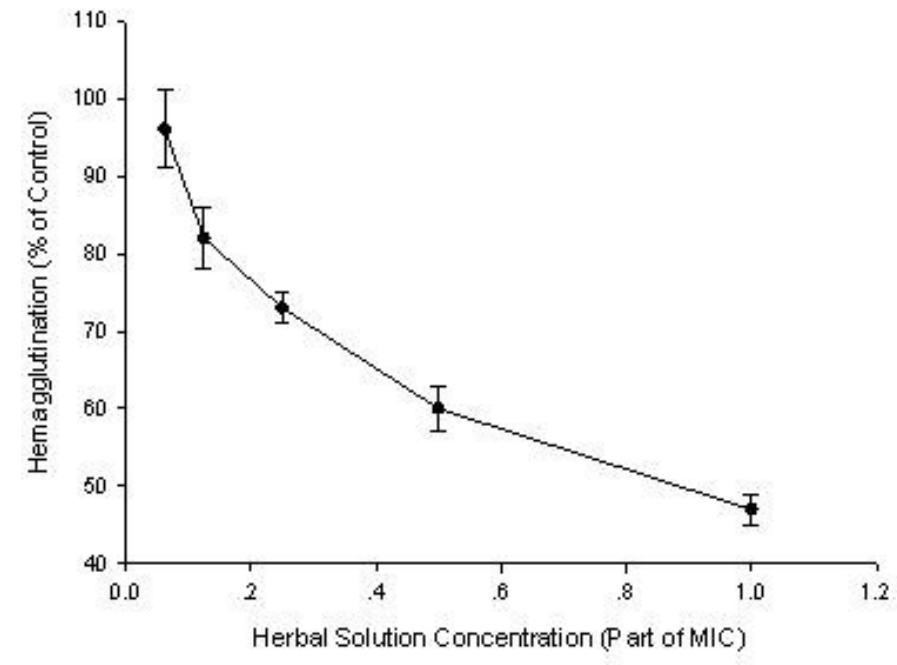

Figure 2: Effect of herbal solution on hemagglutination by E. coli C16 strain.

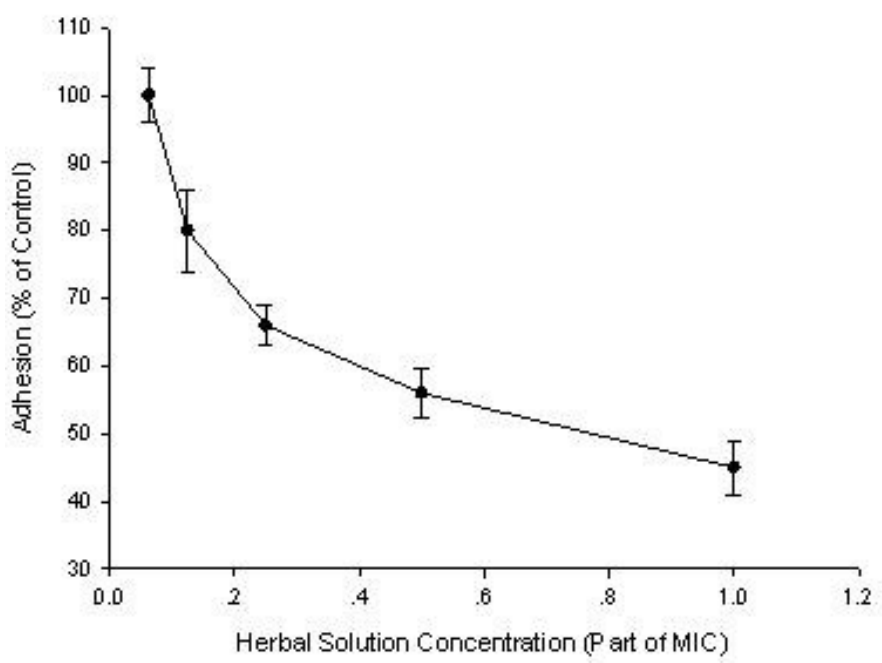

Figure 3: Effect of herbal solution on E. coli $\mathrm{C} 16$ adhesion to human uroepithelial cells. 
of action for Chinese herbs used against pathogens. The decrease in adhesion of $E$. coli culturing in herbal solution can theoretically be caused by several mechanisms, such as filament formation or loss of fimbriae, which need further investigations.

While several previous studies (Tong and Li., 2006; Luo et al., 2006) evaluated the effects of exposure of bacteria to single Chinese herb on attachment to epithelial cells or human red blood cells, this was the first study to investigate the effects that growth of $E$. coli in the presence of a Chinese herbal prescription have on adhesive activity to uroepithelial cells. In this study, we examined the effect of Chinese herbal solution on the adhesive properties of a uropathogenic strain of $E$. coli. We show that Chinese herbal solution has significant effect on the rate of bacterial growth and markedly reduces bacterial adherence.

Even if the herbal solution is efficacious, it may not be possible to determine the active substances immediately, particularly in herbal solution that contains many compounds. Many powerful interventions, such as penicillin and smallpox vaccination, were accepted well before their mechanisms were understood (Wynder, 1994). So lack of knowledge about active substances need not prevent the use of efficacious treatments. In this case, the multi-herb formula is prepared in decocted extracts. One has to expect the possibility that some chemical interactions take place among natural constituents existing in the component herbs of the formula during decoction. Decoction may change the extraction rates of the active ingredients and/or produce new artificial substances, which may then exhibit new pharmacological activities. However, a mixture of several crude extracts could have greater beneficial effects compared with a single plant extract if properly used. First, crude herbs given in combination could act synergistically. Second, they could have unknown interactions but could interact to diminish possible adverse side effects of one or more of the components. Finally, their combination could prevent the gradual decline in effectiveness observed when single herbs are given over long periods of time (Matsuo et al., 1994). So these Chinese herbs could be recommended as an alternative and benificial treatment of UTI.

\section{Acknowledgment}

The research was funded by the Jilin Provincial Science \& Technology Department. We thank Hewei Wei M.D., Yanming Chen M.D. for helpful assistance in preparing the manuscript.

\section{References}

1. Beachey EH (1981). Bacterial adherence: adhesin-receptor interactions mediating the attachment of bacteria to mucosal surface. J Infect Dis, 143: 325-345.

2. Edén CS, Hanson LA, Jodal U, Lindberg U, Akerlund AS (1976). Variable adherence to normal human urinary-tract epithelial cells of Escherichia coli strains associated with various forms of urinary-tract infection. Lancet, 1: 490-492.

3. Kahlmeter G (2003). An international survey of the antimicrobial susceptibility of pathogens from uncomplicated urinary tract infections: the ECO.SENS Project. J Antimicrob Chemother, 51: 69-76.

4. Kallenius G, Mollby R, Svenson SB, Winberg J, Lundblad A, Svensson S, Cedergren B (1980). The Pk antigen as receptor for the haemagglutinin of pyelonephritic Escherichia coli. FEMS Microbiol Lett, 7: 297-302.

5. Kärkkäinen UM, Kauppinen J, Ikäheimo R, Katila ML and Siitonen A (1998). Rapid and specific detection of three different $\mathrm{G}$ adhesin classes of P-fimbriae in uropathogenic Escherichia coli by polymerase chain reaction. $J$ Microbiol Methods, 34: 23-29.

6. Korhonen TK (1979). Yeast cell agglutination by purified enterobacterial pili. FEMS Microbiol Lett, 6: 421-425. 
7. Lao L (1999). Traditional Chinese Medicine. In. Essentials of Complementary and Alternative Medicine. Jonas WB, Levin JS, Eds. Baltimore, Md., Lippincott Williams and Wilkins; pp. 216-232.

8. Luo YJ, Zeng ZL, Yang JQ, Yang L, Wang SL (2006). Elimination of resistance of E.coli to fluoroquinolones by Chinese herbal medicine. J Tradit Chi Vet Med, 25: 7-9.

9. Matsuo R, Ball MA, Kobayashi M, Herndon DN, Pollard RB, Suzuki F (1994). Effects of a traditional Chinese herbal medicine, Kanzo-Bushi-To, on the resistance of thermally injured mice infected with herpes simplex virus type 1. Int J Immunopharmacol, 16: 855-863.

10. Olsson O, Bergström S, Normark S (1982). Identification of a novel ampC beta-lactamase promoter in a clinical isolate of Escherichia coli. EMBO J, 1: 1411-1416.

11. Tong YQ, Li H (2006). In-vitro Antibacterial Activity of the Combination of Herba Violae and Herba Taraxaci in Different Proportions. J Guangzhou University of TCM, 23: 487-492.

12. Wynder EL (1994). Studies in mechanism and prevention: striking a proper balance. Am J Epidemiol, 139: $547-549$. 